\title{
A CASE STUDY OF INTER-ARRIVAL TIME DISTRIBUTIONS OF CONTAINER SHIPS
}

Tu-Cheng Kuo

Associate Professor, Department of Aviation and Maritime Management, Chang Jung University, Tainan, Taiwan 396, R.O.C.

Wen-Chih Huang

Professor, Department of Harbor and River Engineering, National Taiwan Ocean University, Keelung, Taiwan 202,

R.O.C., huangwc@mail.ntou.edu.tw

Sheng-Chieh Wu

Doctor Candidate, Department of Harbor and River Engineering, National Taiwan Ocean University, Keelung, Taiwan 202, R.O.C.

Pei-Lun Cheng

Doctor Candidate, Department of Harbor and River Engineering, National Taiwan Ocean University, Keelung, Taiwan 202, R.O.C.

Follow this and additional works at: https://jmstt.ntou.edu.tw/journal

Part of the Engineering Commons

\section{Recommended Citation}

Kuo, Tu-Cheng; Huang, Wen-Chih; Wu, Sheng-Chieh; and Cheng, Pei-Lun (2006) "A CASE STUDY OF INTER-ARRIVAL TIME DISTRIBUTIONS OF CONTAINER SHIPS," Journal of Marine Science and Technology. Vol. 14: Iss. 3, Article 4. DOI: $10.51400 / 2709-6998.2069$

Available at: https://jmstt.ntou.edu.tw/journal/vol14/iss3/4

This Research Article is brought to you for free and open access by Journal of Marine Science and Technology. It has been accepted for inclusion in Journal of Marine Science and Technology by an authorized editor of Journal of Marine Science and Technology. 


\section{A CASE STUDY OF INTER-ARRIVAL TIME DISTRIBUTIONS OF CONTAINER SHIPS}

\section{Acknowledgements}

The authors would like to thank the National Science Council of the Republic of China for its support of the research NSC 89-2213-E-019-004 and NSC 89-2213-E-019-022. Some results of this paper are parts of those studies. 


\title{
A CASE STUDY OF INTER-ARRIVAL TIME DISTRIBUTIONS OF CONTAINER SHIPS
}

\author{
Tu-Cheng Kuo*, Wen-Chih Huang**, Sheng-Chieh Wu***, and Pei-Lun Cheng***
}

Key words: port queuing system, arrival time distribution, goodness-of-fit test, container liner.

\section{ABSTRACT}

Given the recent prevalence of periodical container liners, the applicability of related models of widely applied queuing theory is left in doubt. Since they focus on marine liners, the distribution pattern is always considered to be a deterministic distribution for periodical schedule. In order to investigate the distribution patterns of container liners, observation units are segmented into single shipping liners, single berths, single container terminals and entire ports. The evolution of the ship arrival distribution pattern and the goodness-of-fit test for observation are based on the ship dynamic data of international harbors in Taiwan. This study aims to implement tests for public and dedicated container berths by comparing the variance in the patterns and characteristics of the ship arrival distributions. The ship inter-arrival distribution in the foregoing systems was found to follow the Erlang distribution; its distribution coefficient $(k)$, changed by observation system, tends to decrease as the system's scale grows.

\section{INTRODUCTION}

The ship arrival distribution test is a vital piece of basic research for port planning, and is also a basis for theoretical queuing models in port capacity analysis and for the choice of the distribution pattern in the simulation approach. The test result of the ship arrival distribution will influence the choice of port queuing system, which subsequently influences relevant variables measured from such models. Given the recent prevalence of periodical container liners, the applicability of related models to the widely applied queuing theory $(M / M / N$, $\left.M / E_{k} / N\right)$ is left in doubt. Other researchers have delivered similar suspicions, although related publications based on practical studies and relevant influence analy-

Paper Submitted 10/12/05, Accepted 02/09/06. Author for Correspondence: Wen-Chih Huang. E-mail: huangwc@mail.ntou.edu.tw.

*Associate Professor, Department of Aviation and Maritime Management, Chang Jung University, Tainan, Taiwan 396, R.O.C.

**Professor, Department of Harbor and River Engineering, National Taiwan Ocean University, Keelung, Taiwan 202, R.O.C.

***Doctor Candidate, Department of Harbor and River Engineering, National Taiwan Ocean University, Keelung, Taiwan 202, R.O.C. sis are quite few in number. The purpose of this paper is to correct this misconception, and to find the ship inter-arrival distribution in the foregoing systems.

Since it is titled as the liner ship, some hold that the distribution pattern should be subordinate to the deterministic distribution for its periodical arrival. The aforesaid viewpoint is simply for one periodical liner, but a shipping company's berth may operate more than one shipping line; likewise, a container terminal possibly consists of various berths, belonging to different shipping companies, while a port includes many container terminals for diverse, dedicated and public use. Accordingly, after many periodical shipping lines are merged, further analysis and verification are required to define the statistical pattern of the ship arrival time distribution. Regarding this issue, this study, based on the ship dynamic data of international ports in Taiwan, will segment the distinct systems as follows: (1) single shipping line, (2) single berth, (3) single container terminal, and (4) entire port, to implement the goodness-of-fit test and analyze the container ship interarrival time or the number of ships arriving during a unit of time. This study also investigates the evolution of the ship arrival distribution pattern by observation systems. Secondly, the ship arrival distribution pattern has changed from the traditionally accepted randomization to dedicated berth owners' arrangement of arrival dates. In consideration of this, this study will also implement tests for dedicated and public container berths by comparing the variance in the patterns and characteristics of their ship arrival distributions.

\section{LITERATURE REVIEW}

There is considerable literature regarding research into ship arrival distribution. In this section, such literature will be discussed as follows in the order of its publication dates. Plumlee [12] took Ecuador's ports as subjects and applied a mathematical statistical approach to investigate the ship arrival distribution pattern. According to his analysis, if the analysis is based on the unit times of day and hour, both results are quite similar and both actual ship arrival distributions approximate to 
the Poisson probability distribution. Yet his analysis of the ship arrival distribution adopted Descriptive statistics, which lack the rigor of other statistical tests. Nicolaou [10] found, in their study, that the distribution conforms to random arrival of Poisson distribution if all the berths in the port are deemed integral. Thus, the random rule of the Poisson distribution is applicable to irregular ship arrivals. Additionally, UNCTAD [19] and Noritake and Kimura [11] have proved that the Erlang distribution is the best way to describe the service time of irregular ship arrivals. With regard to some dedicated berths, such as container berths, in this paper there may be a larger order of $k$, so an Erlang distribution of $k=3$ was applied for descriptive purposes in this study.

Kozan [7] analyzed the data from the ship-loading company of the Fisherman Island container terminal of Brisbane, Australia, in which the information on every ship that arrived had been recorded for over two years. It was indicated in this study that ship arrival conforms to the exponential distribution, passing the Chi-Square goodness-of-fit test. Won and Yong [20] used the object-oriented simulation software SIMPLE ${ }^{++}$to construct a simple container terminal, which was a reduced system of a real terminal in the port of Pusan in Korea, and analyzed the performance of the system. That study also discovered that the inter-arrival time of the ships follows the exponential distribution, and the average arrival rate $\lambda$ is 10 hours. Moreover, the operation time of loading and unloading containers by Gantry crane follows the exponential distribution, and its average service rate is 2 minutes.

Shabayek and Yeung[15] incorporated the Witness simulation software to develop a simulation model for the Kwai Chung container terminals in Hong Kong. That study also discovered that the inter-arrival time of the ships in Kwai Chung follows the exponential distribution, and the service time follows the 117-stage Erlang distribution. Kia et al. [6] studied a set of realtime data regarding the arrival/departure of ships from a container terminal in the port of Melbourne in Australia, and investigated and compared the performances of two different operational systems via a simulation model. Based on a Chi-square test at $95 \%$ confidence level, that study discovered that the ships' inter-arrival time fitted an exponential distribution with $1 / \lambda=23.37$ hour. In contrast, the Chi-square test indicated that the vessel service time did not fit either the normal or the exponential distribution, and based on the data, a $k$-stage Erlang distribution (with $k=4$ ) was finally used for the service time.

In addition to the abovementioned studies, Mettam [9], Jones and Blunden[5], Agerschou and Korsgaard [1], De Weille and Ray [3], Huang and $\mathrm{Wu}$ [4] etc. have proved $M / M / S(\infty)$ and $M / E_{k} / S(\infty)(k=2$ or 3$)$ to be the best queuing model to describe the characteristics of ships in ports, which proves the feasibility of the queuing model applied in the port system. The queuing model is displayed by the symbols $A / B / S(N)$, while $S$ symbolizes the berth, $A$ symbolizes the ship inter-arrival distribution, $B$ symbolizes the service time distribution, and $N$, the number of ships that have arrived. When $M$ represents the inter-arrival and follows the exponential Distribution, and $E_{k}$ represents the stage number $k$ in an Erlang distribution, if $k=1$, then the Erlang distribution is equal to an exponential distribution $\left(E_{1}=M\right)$; if $k=\infty$, then it is equal to a deterministic distribution.

According to the literature review, past studies have only taken a particular subsystem (a berth, a terminal or a port) in the port system into consideration. No publication has yet discussed the course of evolution for arrival time distribution patterns in the port queuing system from marine liner to whole port. Therefore, there is a common misunderstanding that the arrival time distribution of a periodical container ship liner is a deterministic distribution. The following sections of this paper will identify the conception of arrival time distribution patterns in the port system.

\section{PROBABILITY DISTRIBUTION AND TEST APPROACH}

\section{Probability distribution pattern}

Since this study focuses on the probability distribution pattern of the arrival distribution for periodical container liners, some patterns of common arrival distributions will be outlined in this section, including the Erlang distribution and the Exponential distribution. Because the Gamma distribution is equal to the other two probability distribution patterns in some special circumstances, this section will first illustrate the Gamma distribution with its probability density function.

\section{(1) Gamma distribution}

The probability density function of the Gamma distribution is as follows

$$
f(t)=\frac{\lambda}{\Gamma(\alpha)}(\lambda t)^{\alpha-1} e^{-\lambda t}, \mathrm{t}>0, \lambda>0, \alpha>0
$$

where $\Gamma(\alpha)=\int_{0}^{\infty} t^{\alpha-1} e^{-t} d t, \alpha>0$

The cumulative probability density function is as follows 


$$
F_{t}(t)=1-e^{-\lambda t} \sum_{i=0}^{\alpha-1} \frac{(\lambda t)^{i}}{i !}, t>0, \alpha \text { integer }
$$

In Eq. (1), if the parameter $\alpha$ is not an integer, the equation is subordinate to the Gamma distribution. On the contrary, if the parameter $\alpha$ is a positive integer, the equation is subordinate to the Erlang distribution. The parameter $\alpha$ is the approximate value of the parameter $k$ in the Erlang distribution $[13,16]$.

\section{(2) Erlang distribution}

If there is an cumulative probability density function of variable $t$, as in Eq. (3), where $\lambda>0$ and is a constant number, it can be said that the variable $t$ follows the $k$-stage Erlang distribution [14].

$$
F(t)=\left\{\begin{array}{cc}
1-\sum_{i=0}^{k-1} e^{-\lambda t} \frac{(\lambda t)^{i}}{i !}, & t \geq 0 \\
0 \quad, t<0
\end{array}\right.
$$

From the first derivative of the foregoing equation, the probability density function is then obtained:

$$
f(t)=\frac{\lambda(\lambda t)^{k-1}}{(k-1) !} e^{-\lambda t}, t \geq 0
$$

\section{(3) Exponential distribution}

Equation (5) can be obtained when the parameter $k=1$ for Eq. (4):

$$
f(t)=\lambda e^{-\lambda t}, t \geq 0
$$

The foregoing equation is the probability density function of the exponential distribution $[2,15]$.

If the inter-arrival time follows the exponential distribution in Eq. (5), the number of ships arriving in a unit of time follows the Poisson distribution, or the arrival distribution is random. In accordance with the literature related to the queuing theory, the characteristic of the Erlang distribution are such that when the value $k$ increases, the Erlang distribution accordingly becomes symmetrical; when $k$ 30, the Erlang distribution approximates the Normal distribution; and when $k$ $\rightarrow \infty$, the Erlang distribution turns into a Deterministic distribution The evolution process through which the probability density function of the Erlang distribution develops as the $k$ value increases (from exponential distribution to Normal distribution to Deterministic distribution) is illustrated in Figure 1. In addition, a basic concept of the Erlang distribution that needs to be understood is that in multiple service station systems,

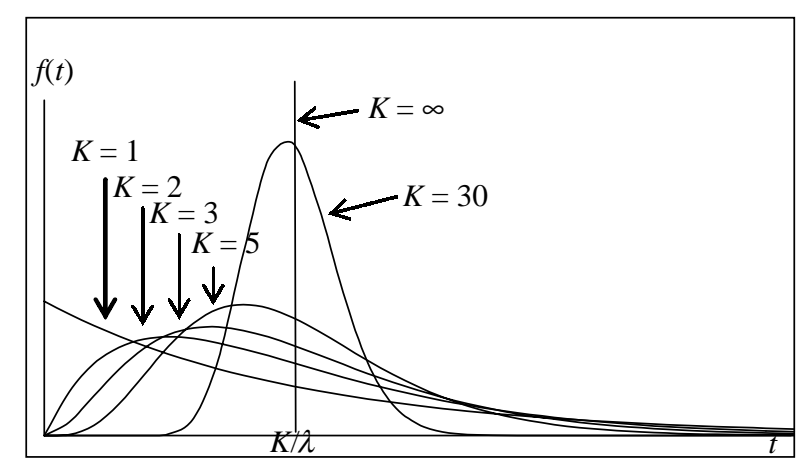

Fig. 1. The evolution process of the erlang distribution as the $k$ value increases.

any inter-arrival of the service station follows the Erlang distribution of $k$ values, if the inter-arrival of the entire system is an exponential distribution. This means that the exponential distribution is the total of multiple independent $k$-stage Erlang distributions [8, 17, 18] .

\section{Discussion of test approach}

The goodness-of-fit test of statistical analysis is applied for the ship arrival distribution test in this study. According to the literature review, the most appropriate approaches are the Chi-Square goodness-of-fit test and the K-S test. The test results with these two approaches are illustrated respectively below.

\section{(1) Chi-Square Goodness-of-fit}

Test The sample in this paper should be divided into groups before applying this approach to the ship arrival distribution. However, the grouping always results in the message being missed, as this study must be implemented with multi-time tests and waste considerable time in determining the group interval for the best results. Thus, grouping (selecting the number of groups and group interval) is a critical factor for the Chi-Square goodness-of-fit test. Table 1 shows the results of the Chi-Square goodness-of-fit test in this study. In selecting the number of groups and the group interval, it is necessary to carry out the test with the reference value of the formula $1+3.3 \log (n)$ in advance, and then implement multi-time tests with a trial-anderror approach referring to the range of the reference value. Taking the entire port test as an example, different numbers of groups (34 and 27 respectively) and group intervals ( 0.2 hours and 0.25 hours respectively) lead to different test results (the group at the interval of 0.25 hours failed the Chi-Square goodness-of-fit test at the $95 \%$ confidence level), and the effect is not obvious, 
as the formula is for statistical reference only.

\section{(2) Kolmogorov-smirnov test}

The major approach is to present the integral information by applying re-sorting of the sample data and cumulative probability sampling instead of grouping, which avoids missing data and leads to a more convenient test. The K-S test is used for goodness-of-fit testing and features a better test performance than ChiSquare goodness-of-fit.

In this study, it has been found that in the application of the Chi-square goodness-of-fit test, the ship arrival distribution differs as the size of the group and the group interval vary. Thus, it takes more time; thus it is not recommended to implement this test for considerable quantities. Because of its greater convenience, the K-S test is applicable for the test analysis of large quantities. However, there is a drawback, in that the $\mathrm{K}$ $\mathrm{S}$ test is hard to pass with a larger number of test samples
As shown in Table 2, which compares the K-S test and the Chi-Square goodness-of-fit test, if the number of ships is relatively small (404 ships in a singular berth), there is no difference between both tests; but if the number is larger $(1,423$ ships in the container terminal and 7,729 ships in the entire port), it is hardly possible to pass the $\mathrm{K}-\mathrm{S}$ test at $95 \%$ confidence level. After observing the comparison of the Chi-Square goodnessof-fit test and the contrasts highlighted in Table 1 and Table 2, larger sample sizes may be accounted for using the stricter threshold of the K-S test. From this study, it is suggested that the threshold limit value should be modified properly for larger sampling, in order to conform to realistic needs.

\section{TEST RESULTS AND ANALYSIS OF ARRIVAL DISTRIBUTION OF DISTINCT SYSTEMS IN KAOHSIUNG}

This study undertakes the segmentation of distinct

Table 1. Chi-square test results of the ship arrival time distribution in Kaohsiung

\begin{tabular}{|c|c|c|c|c|c|c|c|c|c|c|c|c|}
\hline \multirow{3}{*}{$\begin{array}{l}\text { Items } \\
\text { The number of ships } \\
\text { The interval of arrival time (hrs) }\end{array}$} & \multicolumn{4}{|c|}{ Single berth } & \multicolumn{4}{|c|}{$\begin{array}{l}\text { Single terminal } \\
\text { (Dedicated berth } \\
\quad \# \mathrm{~A}-\# \mathrm{C})\end{array}$} & \multicolumn{4}{|c|}{ Entire port } \\
\hline & \multicolumn{4}{|c|}{404} & \multicolumn{4}{|c|}{1423} & \multicolumn{4}{|c|}{7729} \\
\hline & \multicolumn{2}{|c|}{4} & \multicolumn{2}{|c|}{8} & \multicolumn{2}{|c|}{1} & \multicolumn{2}{|c|}{2} & \multicolumn{4}{|c|}{0.25} \\
\hline Number of group & \multicolumn{2}{|c|}{15} & \multicolumn{2}{|c|}{8} & \multicolumn{2}{|c|}{23} & \multicolumn{2}{|c|}{15} & \multicolumn{4}{|c|}{27} \\
\hline $\begin{array}{l}\text { The formula of the number } \\
\text { of group }(1+3.3 \log (n))\end{array}$ & \multicolumn{2}{|c|}{9.6} & \multicolumn{2}{|c|}{9.6} & \multicolumn{2}{|c|}{11.4} & \multicolumn{2}{|c|}{11.4} & \multicolumn{4}{|c|}{13.8} \\
\hline The $k$-stage erlang dist. & \multicolumn{2}{|c|}{2} & \multicolumn{2}{|c|}{2} & \multicolumn{2}{|c|}{1} & \multicolumn{2}{|c|}{1} & \multirow{2}{*}{\multicolumn{4}{|c|}{1}} \\
\hline$X^{2}$ value & 23.06 & 8.78 & 30.81 & 22.70 & 45.35 & 41.55 & & & & & & \\
\hline Significance level $\alpha$ & 0.05 & 0.005 & 0.05 & 0.005 & 0.05 & 0.005 & 0.05 & 0.005 & 0.05 & 0.005 & 0.05 & 0.005 \\
\hline The value of threshold & 22.36 & 29.82 & 12.59 & 18.55 & 32.67 & 41.40 & 22.36 & 29.82 & 48.57 & 58.91 & 37.65 & 46.93 \\
\hline Passed in the test or not & $\mathrm{N}$ & $\mathrm{Y}$ & $\mathrm{Y}$ & $\mathrm{Y}$ & $\mathrm{Y}$ & $\mathrm{Y}$ & $\mathrm{N}$ & $\mathrm{Y}$ & $\mathrm{Y}$ & $\mathrm{Y}$ & $\mathrm{N}$ & $\mathrm{Y}$ \\
\hline
\end{tabular}

Table 2. Comparison between the results of K-S test and Chi-Square test

\begin{tabular}{|c|c|c|c|c|c|}
\hline \multicolumn{3}{|c|}{ Scale } & Single berth & $\begin{array}{c}\text { Single terminal } \\
\text { (Dedicated berth } \\
\text { \#A-\#C) }\end{array}$ & Entire port \\
\hline \multicolumn{3}{|c|}{$\begin{array}{l}\text { The number of ships } \\
\text { The } k \text {-stage erlang dist. }\end{array}$} & $\begin{array}{c}404 \\
2\end{array}$ & $\begin{array}{c}1423 \\
1\end{array}$ & $\begin{array}{c}7729 \\
1\end{array}$ \\
\hline $\mathrm{K}-\mathrm{S}$ test & $\begin{array}{l}\text { The max error probability } \\
\text { The value of threshold } \\
\text { (Significance level } \alpha \text { ) } \\
\text { Passed in the test }(\alpha)\end{array}$ & $\begin{array}{l}0.05 \\
0.01\end{array}$ & $\begin{array}{c}0.052 \\
0.067 \\
0.081 \\
0.05\end{array}$ & $\begin{array}{c}0.038 \\
0.036 \\
0.043 \\
0.01\end{array}$ & $\begin{array}{l}0.027 \\
0.015 \\
0.018 \\
\mathrm{~N}\end{array}$ \\
\hline $\begin{array}{l}\text { Chi-Square } \\
\text { test }\end{array}$ & $\begin{array}{l}\text { The total error probability } \\
\text { The value of threshold } \\
\text { (Significance level } \alpha \text { ) } \\
\text { Passed in the test }(\alpha)\end{array}$ & $\begin{array}{l}0.05 \\
0.01\end{array}$ & $\begin{array}{c}8.78 \\
12.59 \\
16.81 \\
0.05\end{array}$ & $\begin{array}{c}30.81 \\
32.67 \\
38.93 \\
0.05\end{array}$ & $\begin{array}{c}45.35 \\
48.57 \\
56.01 \\
0.05\end{array}$ \\
\hline
\end{tabular}


systems such as entire ports, container terminals, berth and shipping lines, etc. of the international ports in Taiwan, to implement the goodness-of-fit test. Following the test approaches outlined in the last section, although K-S test is hard to pass with a larger sample, results acquired are similar to those attained from the Chi-Square goodness-of-fit test when the sample size is smaller. In consideration of the large quantities of tests implemented in individual berths and individual container terminal in the entire port, it is decided to adopt the K-S as the main test in this study, and use the ChiSquare goodness-of-fit test when the sample size is larger or has failed the K-S test even though the probability distribution graphs are similar. In this section, the port of Kaohsiung is taken as an example and the illustration will be based on distinct systems.

\section{Shipping line}

As the container berth has recently become available for lease and bulk goods dealers, by contracting with the Port Authority, have built berths for different shipping lines, the operation of shipping dates is possi- bly presented by the periodical liner. However, a shipping company may operate more than one shipping line; after many periodical liners are merged, further analysis and verification are required in order to define the statistical pattern of the ship arrival time distribution. To probe into this issue, the arrival pattern test is implemented on one singular shipping line belonging to a shipping company. In this study, the test is conducted for the arrival distribution of the westward line of shipping company $\mathrm{E}$ in the port of Kaohsiung; the test result is shown in Table 3, Figure 2, and reveals that the arrival pattern of individual shipping lines conforms to the Gamma distribution of the approximate Erlang parameter value $k=5.462$.

\section{Berth}

\section{(1) Public berth}

The public berth of Container terminal I in the port of Kaohsiung is selected to serve as the test object. The test result is shown in Table 4 and Figure 3, from which it can be seen that the ship arrival distribution pattern of

Table 3. The K-S test results of single shipping line

\begin{tabular}{|c|c|c|c|c|c|c|c|c|c|c|c|c|c|}
\hline \multirow[t]{2}{*}{ Scale } & \multirow{2}{*}{$\begin{array}{l}\text { The number } \\
\text { of ships }\end{array}$} & \multirow[t]{2}{*}{ Average } & \multirow{2}{*}{$\begin{array}{l}\text { Standard } \\
\text { deviation }\end{array}$} & \multirow{2}{*}{$\begin{array}{l}\text { The approximate } \\
k \text {-stage erlang dist. }\end{array}$} & \multicolumn{5}{|c|}{ The max error probability } & \multicolumn{4}{|c|}{$\begin{array}{l}\text { The value of threshold } \\
\text { (Significance level } \alpha \text { ) }\end{array}$} \\
\hline & & & & & 1 & 2 & 3 & 4 & 5 & 6 & 0.1 & 0.05 & 0.01 \\
\hline $\begin{array}{c}\text { Single } \\
\text { shipping } \\
\text { line }\end{array}$ & 101 & 83.92 & 35.9 & $5.462^{\mathrm{a}}$ & 0.345 & 0.218 & 0.146 & 0.097 & 0.062 & 0.064 & +0.121 & 0.135 & 0.162 \\
\hline
\end{tabular}

a. Data passed in the test of the erlang dist.

Table 4. The K-S test result of the arrival distribution of distinct systems in Kaohsiung

\begin{tabular}{lcccc}
\hline Port queuing system & $\begin{array}{c}\text { The number } \\
\text { of ships }\end{array}$ & Average & $\begin{array}{c}\text { Standard } \\
\text { deviation }\end{array}$ & $\begin{array}{c}\text { The approximate } \\
k \text {-stage erlang dist. }\end{array}$ \\
\hline Entire port & 7729 & 1.14 & 1.22 & $0.875^{\mathrm{a}}$ \\
Public terminal (\#40 - \#43) & 532 & 16.44 & 15.58 & $1.113^{\mathrm{b}}$ \\
Dedicated terminal & 1423 & 6.16 & 5.75 & $1.144^{\mathrm{b}}$ \\
(Dedicated berth \#A - \#C) & 84 & 102 & 75.7 & $1.798^{\mathrm{b}}$ \\
Public berth \#40 & 73 & 119 & 120 & $0.995^{\mathrm{b}}$ \\
Public berth \#41 & 215 & 40.5 & 50.1 & $0.655^{\mathrm{b}}$ \\
Public berth \#42 & 157 & 55.6 & 133 & 0.175 \\
Public berth \#43 & 404 & 21.58 & 15.14 & $2.032^{\mathrm{b}}$ \\
Dedicated berth \#A & 570 & 15.3 & 13.17 & $1.35^{\mathrm{b}}$ \\
Dedicated berth \#B & 443 & 19.73 & 13.63 & $2.096^{\mathrm{b}}$ \\
Dedicated berth \#C & 101 & 83.92 & 35.9 & $5.462^{\mathrm{b}}$ \\
Single shipping line & & & \\
\hline
\end{tabular}

a. Although the data failed in the test but is approximated to the erlang dist.

b. Data passed in the test of the erlang dist. 
the public berth in the port of Kaohsiung approximates to the Erlang distribution with parameter values of $k=$ $0.175 \sim 1.798$; the approximate parameter values are acutely variable among 4 public berths.

\section{(2) Dedicated berth}

Three dedicated berths of the E shipping company, berth A, B and C, are selected to serve as the test objects. The test result is shown in Table 4 and Figure 3, from which it can be seen that the ship arrival distribution pattern of E company's dedicated berth in the port of Kaohsiung approximates to the Erlang distribution of the parameter values $k=1.35 \sim 2.096$; and the approximate parameter values vary indistinctively among these 3 dedicated berths.

\section{Container terminal}

The test of the container terminals is implemented in two parts: public container terminal and dedicated container terminal respectively. While the definition of a container terminal is not based on the actual container terminals found in every port, in considering the characteristic of periodical liner arrival (i.e., a dedicated container terminal is only available for vessels belonging to the owner company or the contracted companies) and the basic definition of queuing theory, segmentation by companies and systems is used in this study. Here, one container terminal of each type, i.e. one for public and one for dedicated use, is selected for the illustration (using \#40 - \#43 as our public container terminal and a shipping company as our dedicated container terminal).

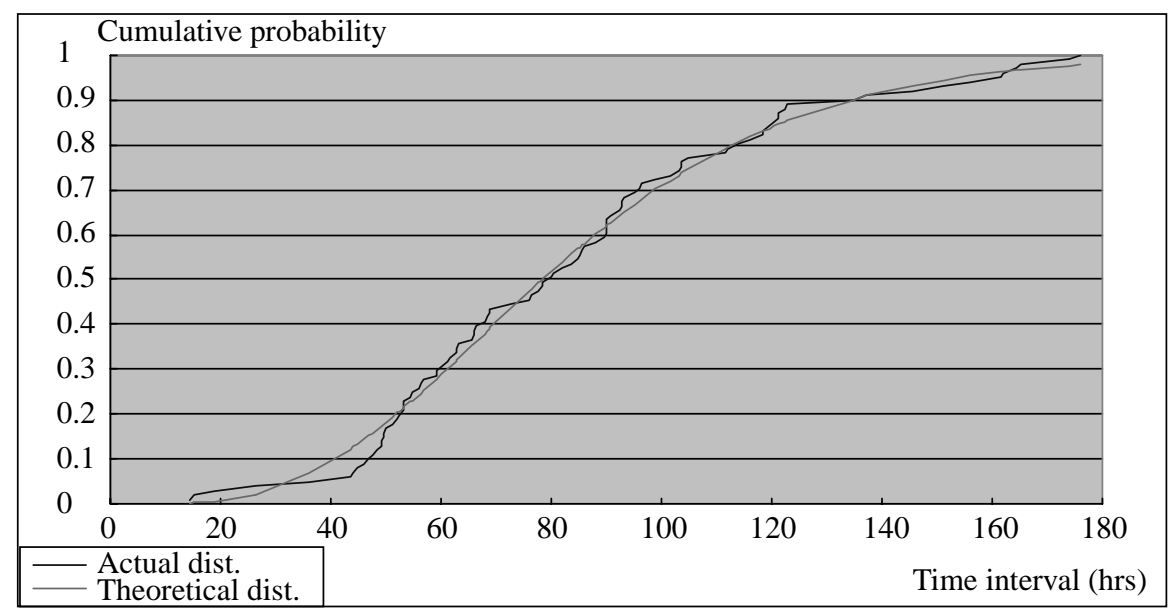

Fig. 2. The container ship arrival time distribution of a single shipping line (K-S test).

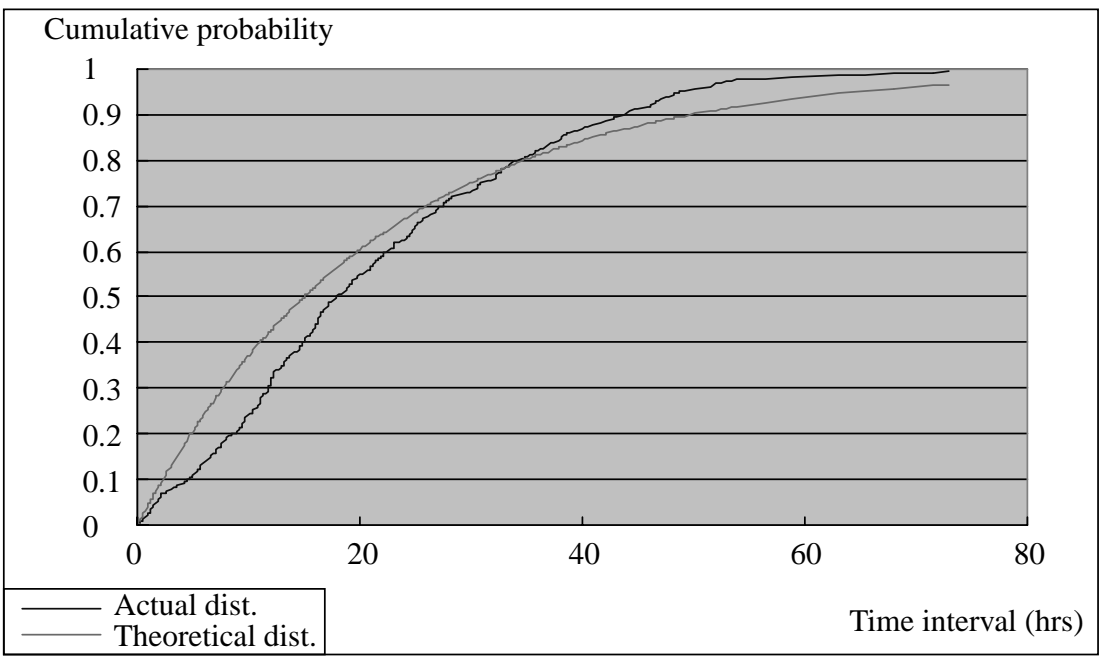

Fig. 3. The container ship arrival time distribution of a single berth (K-S test). 
In the public container terminal at the port of Kaohsiung, as illustrated in Table 4 and Figure 4, the ship arrival distribution also passed the test of the Erlang distribution at a distribution coefficient value of 1 , although its standard deviation is clearly larger than that of the dedicated container terminal. This is because the shipping company can schedule the shipping dates of its vessels, whereas the inter-arrival times for the public container terminal can not be arranged for vessels belonging to various shipping companies, which is why the inter-arrival time for the public container terminal is more scattered.

\section{Entire port}

In 1998, 7,729 ships anchoring throughout the port of Kaohsiung totally passed the test of the Erlang distribution at a distribution coefficient value of 1 , through the Chi-Square goodness-of-fit test, as shown in Tables 1, 2, 4. Figure 5 shows the K-S test results of the periodical container liner arrival distribution for the entire Port of Kaohsiung, from which it may be realized that the actual distribution is similar to the theoretical distribution but fails the K-S test.

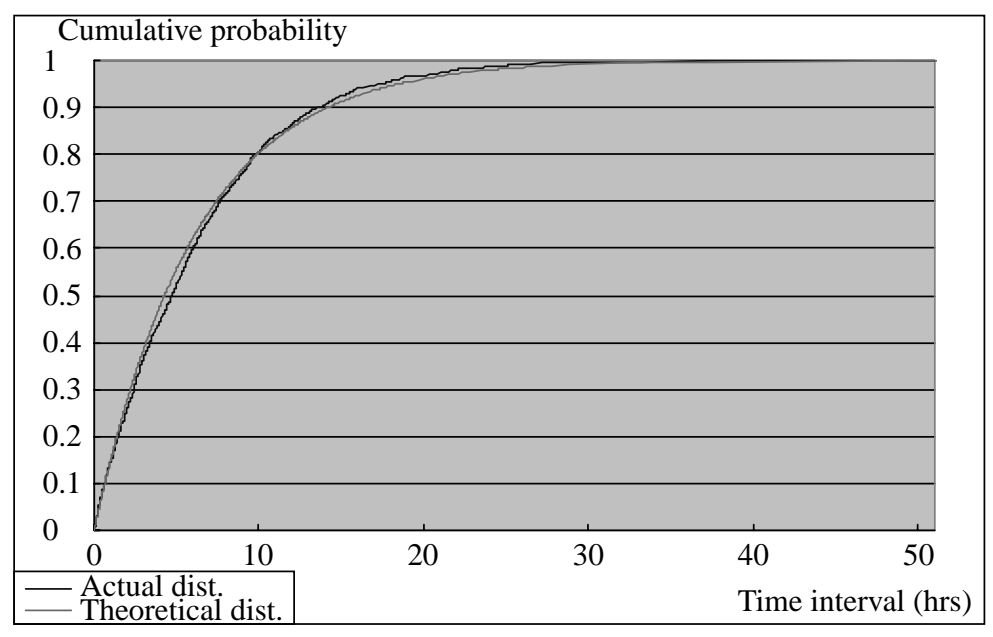

Fig. 4. The ship arrival time distribution for the dedicated container terminal (K-S test).

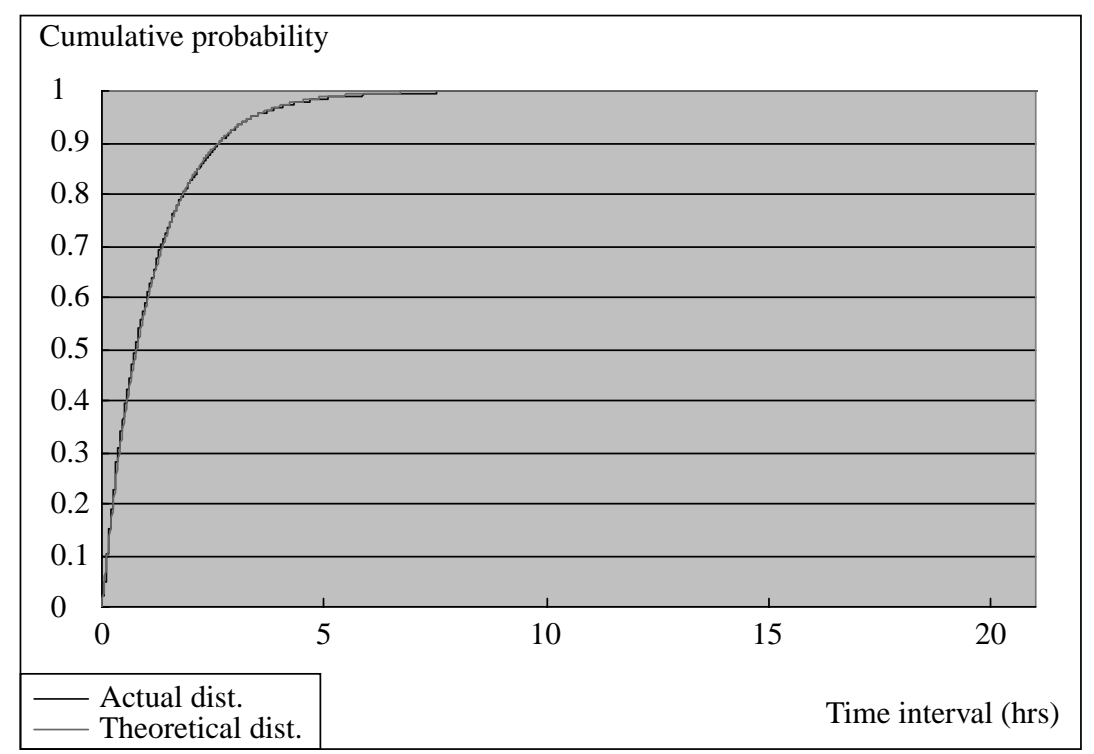

Fig. 5. The container ship arrival time distribution for the entire port (K-S test). 


\section{Discussion}

According the test results, the ship inter-arrival distribution pattern mainly follows the Erlang Dist. and the foregoing related probability distribution discussed in previous sections, and its distribution coefficient $(k)$ is changed by observation system. This study undertakes the segmentation of distinct systems such as a single shipping line, single berth, container terminal, entire port, etc., to implement the goodness-of-fit test, and to implement an analysis on the actual example of container ships in port of Kaohsiung. Consequently, it can be found that the coefficient value $k$ in the Erlang distribution decreases following the foregoing systems, as shown in Figure 6.

Take the single shipping line of a shipping company in the port of Kaohsiung as an example; its ship arrival time distribution follows the Erlang distribution and it has a coefficient value $k$ of 5 , instead of infinity $(k=\infty)$ : the Erlang coefficient value of the deterministic distribution. This indicates that the characteristics of the periodical container liner arrival are indistinct on this single shipping line. If a singular berth is selected as the test object of the arrival distribution, its Erlang coefficient value $\mathrm{k}$ approaches 2 , which is also variable depending on whether the berth is for public or dedicated use. For a public berth, the coefficient $(k)$ has an acute variation and a value less than that for a lease berth. If the container terminal and the entire port are regarded as a system for the ship inter-arrival test, its distribution passes the Erlang distribution test when $k$ is valued one, that is, it is presented as a Poisson random arrival distribution pattern. From the results above, a system with a larger scale tends to have a distribution pattern closer to random. Furthermore, the characteristics of the "periodical" liner are different from those generally acknowledged. Being affected by the delays in the shipping date and the distinct observation system, the distribution pattern of the periodical liner will be changed from the expected periodicity $(k=\infty)$ into a random arrival distribution, as shown in Figure 7.

\section{CONCLUSION}

The periodical container liner operates according to a regular schedule, but its distribution may be influenced by factors such as advanced or delayed sailing dates and distinct observation systems. Furthermore, a shipping company may operate more than one shipping line; when all the shipping lines are merged, this study demonstrates that the ship arrival distribution will be shifted from Singular shipping line $\rightarrow$ Singular berth $\rightarrow$ Singular container terminal $\rightarrow$ Entire port accordingly, from approximately $k=5$ of the Erlang distribution to $k$ $=1$ of the random arrival distribution; and proves that the ship arrival distribution is affected by distinct observation systems.

In respect of different operation patterns, the arrival distributions of the berth and the container terminal are a little different. Regarding the public container

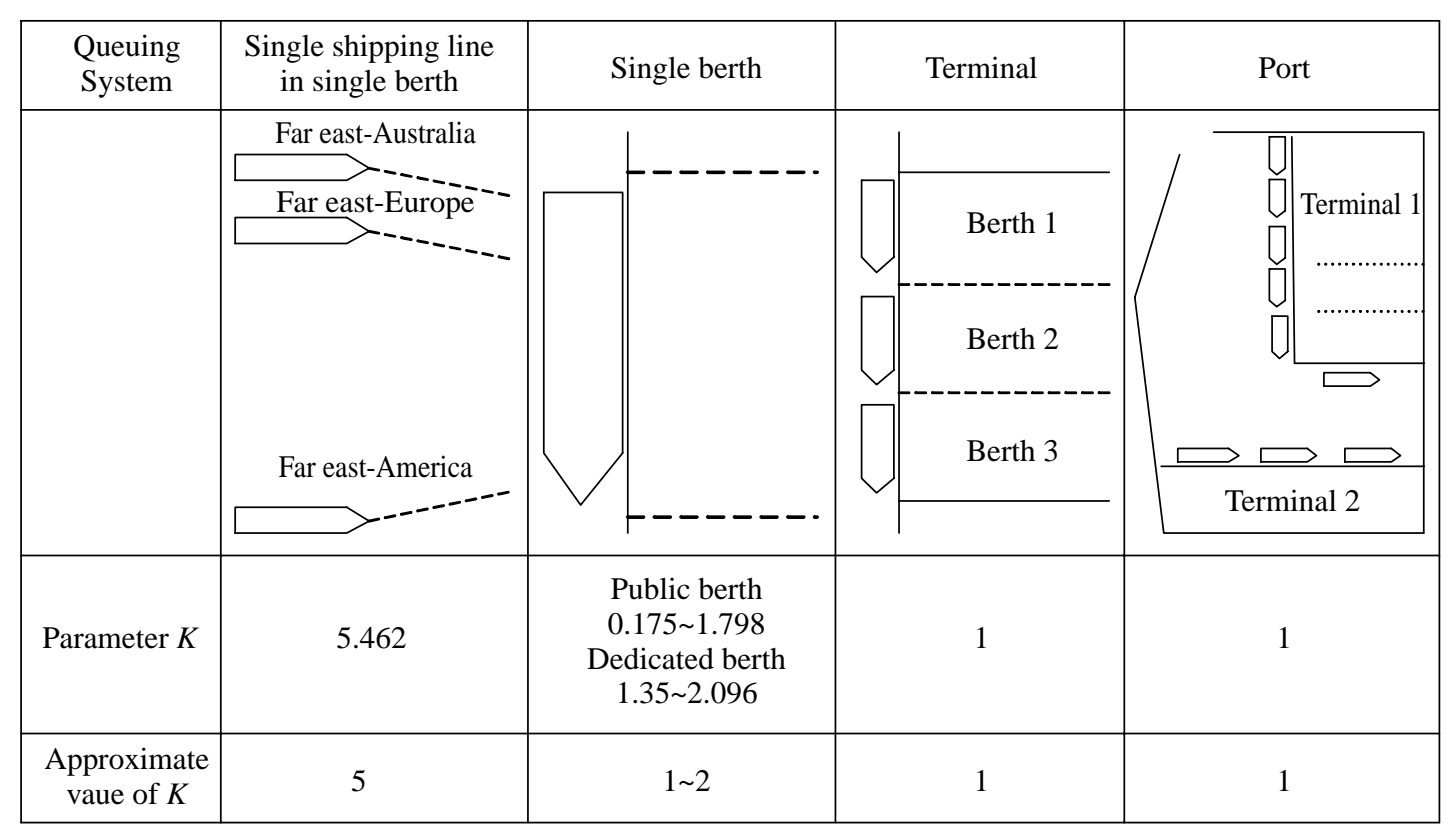

Fig. 6. The relationship between the port system and the parameter $k$ of the erlang distribution. 


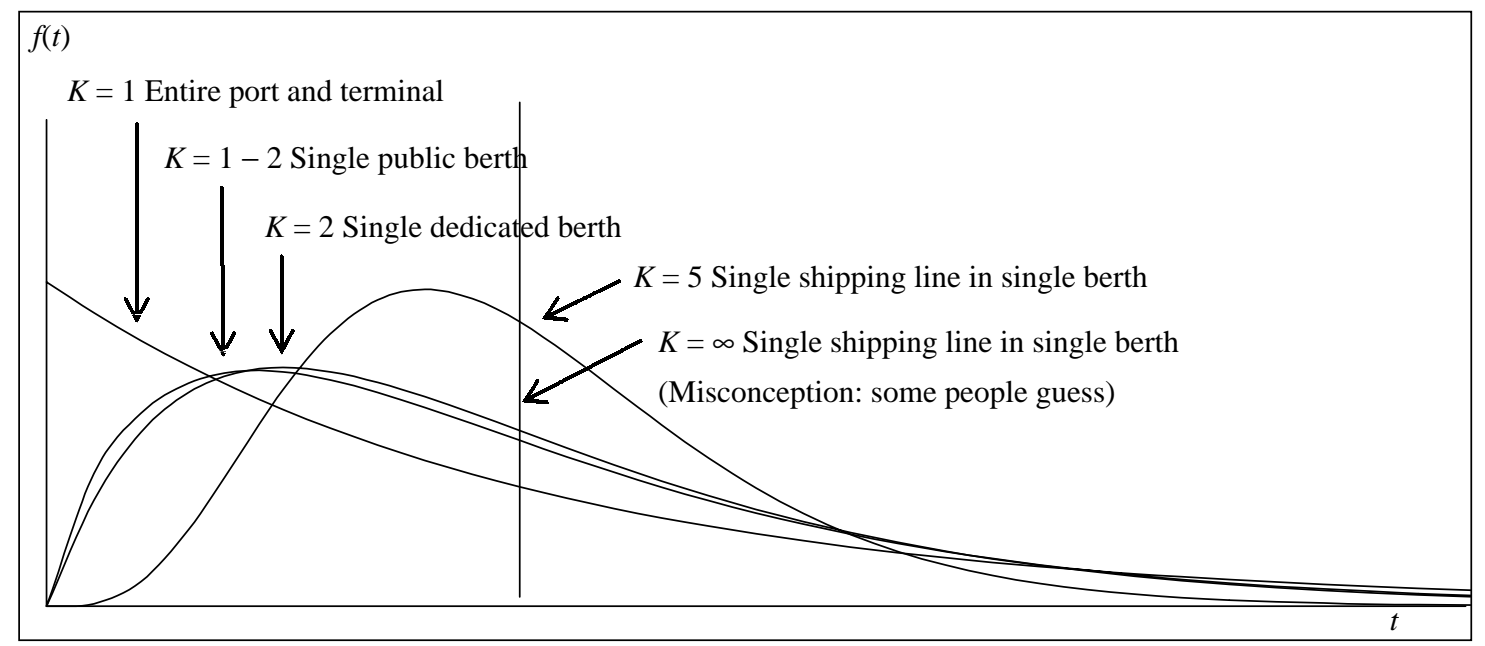

Fig. 7. The container ship arrival time distributions of the various subsystems in the port.

terminal and the lease container terminal in Kaohsiung, their Erlang parameter values are closer but their standard deviations vary acutely; it can be concluded that the inter-arrival time at the public container terminal is more scattered than that of the lease container terminal. The ship arrival distribution varies depending on the test approaches, the number of groups and the group interval. It is not recommended to use the Chi-Square goodness-of-fit test for large quantities of tests because it costs more time. While the K-S test is hard to pass with larger samples, the study suggested that the threshold limit value should be modified appropriately for larger samples, in order to conform to realistic needs.

The definition of the container terminal should be mainly based on the system classification according to the actual queuing system, i.e. the container terminal is defined by every berth of rental shipping companies or the berths in support of each other. Because some ships may anchor at fixed berths, if it is the case following the current classification of container terminals in every port, blending the berths of one container terminal, it would then lead to a contradiction analyzing the port capacity using queuing theory or other mathematic analytical approaches. This study finds that the ship interarrival distribution in the foregoing systems follows the Erlang distribution and its distribution coefficient $(k)$, changed by observation system, and tends to decrease as the system's scale grows.

\section{ACKNOWLEDGEMENTS}

The authors would like to thank the National Science Council of the Republic of China for its support of the research NSC 89-2213-E-019-004 and NSC 89-
2213-E-019-022. Some results of this paper are parts of those studies.

\section{REFERENCES}

1. Agerschou, H. and Korgaard, J., "Systems Analysis for Port Planning," Dock and Harbor Authority, Vol. 49, pp. 411-415 (1969).

2. Barry, P.C. and Moshe, F.F., "The Joint Distribution of Occurrences of Two Interrelated Poisson Processes," European Journal of Operational Research, Vol. 89, pp. 660-667 (1994).

3. De Weille, J. and Ray, A., "The Optimum Port Capacity," Journal of Transport Economics and Policy, Vol. 8, No. 3, pp. 244-259 (1974).

4. Huang, W.C. and Wu, S.C., "The Estimation of the Initial Number of Berths in a Port System Base on Cost Function," Journal of Marine Science and Technology, Vol. 13, No. 1, pp. 35-45 (2005).

5. Jones, J.H. and Blunden, W.R., "Ship Turn-Around Time at the Port of Bangkok," Journal of the Waterways and Harbors Division, Vol. 94, No. 2, pp. 135-148 (1968).

6. Kia, M., Shayan, E., and Ghotb, F., "Investigation of Port Capacity Under a New Approach by Computer Simulation," Computers \& Industrial Engineering, Vol. 42, pp. 533-540 (2002).

7. Kozan, E., "Comparison of Analytical and Simulation Planning Models of Seaport Container Terminals," Transportation Planning and Technology, Vol. 20, pp. 235248 (1997).

8. Lawless, J.F., "Regression Method for Poisson Process Data," Journal of the American Statistical Association, Vol. 82, pp. 808-815 (1987). 
9. Mettam, J.D., "Forecasting Delays to Ships in Port," Dock and Harbor Authority, Vol. 47, pp. 380-382 (1967).

10. Nicalau, S.N., "Berth Planning by Evaluation of Congestion and Cost," Journal of the Waterways and Harbors, Vol. 93, Vol. 4, pp. 107-132 (1967).

11. Noritake, M. and Kimura, S., "Optimum Number and Capacity of Seaport Berth," Journal of Watwerway Port Coastal and Ocean Engineering, Vol. 109, No. 3, pp. 323-329 (1983).

12. Plumlee, C.H., "Optimum Size Seaport," Journal of Waterway and Harbors, Vol. 92, No. 3, pp. 1-24 (1966).

13. Ravindran, A., Operations Research, John Wiley \& Sons, New York (1987).

14. Richard, L.S., "Extreme Value Theory Based on the $r$ Largest Annual Events," Journal of Hydrology, Vol. 86, pp. 27-43 (1986).

15. Shabayek, A.A. and Yeung, W.W., "A Simulation Model for the Kwai Chung Container Terminals in
Hong Kong," European Journal of Operational Research, Vol. 140, pp. 1-11 (2002).

16. Sheldon, M.R., Introduction to Probability Models, Academic Press, Inc. New York (1993).

17. Steute, F.W., "Poisson Processes and a Bessek Function Integral," SIAM Review, Vol. 27, No. 1, pp. 73-77 (1985).

18. Thomas, S.S., "An Analysis of the Trend in GroundLevel Ozone Using Non-Homogeneous Poisson Processes," Atmospheric Environment, Vol. 25B, No. 3, pp. 387-395 (1991).

19. UNCTAD, Port Development: a Handbook for Planners in Developing Countries, United Nations, New York (1985).

20. Won, Y.Y. and Yong, S.C., “A Simulation Model for Container-Terminal Operation Analysis Using an Object-Oriented Approach," International Journal of Production Economics, Vol. 59, pp. 221-230 (1999). 